\title{
A case of I8p deletion syndrome after blepharoplasty
}

This article was published in the following Dove Press journal:

International Medical Case Reports Journal

12 January 2017

Number of times this article has been viewed

\section{Li-juan $X u^{\prime}$ \\ Lv-xian Wu ${ }^{2}$ \\ Qing Yuan ${ }^{3}$ \\ Zhi-gang Lv' \\ Xue-yan Jiang ${ }^{2}$ \\ 'Department of Opthalmology, \\ 2Department of Pediatrics, \\ ${ }^{3}$ Department of Clinical Laboratory, \\ Jinhua Central Hospital, Jinhua, \\ Zhejiang, People's Republic of China}

Correspondence: Lv-xian Wu

Jinhua Central Hospital, No. 35I, Mingyue

Road, Jinhua, Zhejiang 321000, People's

Republic of China

Tel +865798255240

Email jhdaj@I26.com
Objective: The deletion of the short arm of chromosome 18 is thought to be one of the rare chromosomal aberrations. Here, we report a case to review this disease.

Case report: The proband is a five-and-a-half-year-old girl who has had phenotypes manifested mainly by ptosis, broad face, broad neck with low posterior hairline, mental retardation, short stature, and other malformations. Chromosomal analysis for her mother showed a normal karyotype. Her father and younger brother were phenotypically normal.

Result: Phenotypical features were quite similar throughout other cases and in accordance with the usual phenotype of del(18p) suggested within the same cases and among the del(18p) cases described. She underwent blepharoplasty, which improved her appearance.

Conclusion: $18 \mathrm{p}$ deletion syndrome is diagnosed by gene analysis. Plastic surgeries for improving the appearance might be an option for these patients.

Keywords: chromosome, deletion, blepharoplasty

\section{Introduction}

The deletion of part or the entire short arm of chromosome 18 is a rare chromosomal aberration, which is estimated to affect $\sim 1$ in 50,000 live births, with a female to male ratio of 3:2. ${ }^{1-4}$ Since its first description by Jean de Grouchy in $1963,{ }^{5}>150$ cases have been reported.

The clinical features of this syndrome vary from one patient to another, depending on the deletion size and specific breakpoints. The larger the deletion and the closer to the centromeric region of the chromosome, the more severe the anomalies. ${ }^{3}$ The clinical abnormalities include growth deficiency, mental retardation, facial deformity (eg, ptosis, epicanthal folds, low nasal bridge, and large protruding ears), microcephaly, holoprosencephaly, and clinodactyly of the fifth finger. Besides, the discrepancy between verbal and nonverbal performance, as well as dystonias, has also been reported. ${ }^{6,7}$ Though there are diverse phenotypic manifestations, the diagnosis depends mostly on cytogenetic findings. ${ }^{4}$

Two-thirds of del(18p) cases were supposed to originate from de novo pure terminal deletion, while one-third of cases were caused by a de novo unbalanced translocation, malsegregation of a parental translocation or inversion, and a ring chromosome or isochromosome $18 \mathrm{q} \cdot{ }^{8-11}$ Here, we report a girl with del(18p) with variable clinical features, whose facial appearance improved after blepharoplasty. 


\section{Case report}

This study complied with the tenets of the Declaration of Helsinki. The consent form for the publication of this report and the accompanying images has been signed by the parents of the child.

The proband was born with a birth weight of $2,200 \times g$, following a normal gestation and delivery without complications, the first child of a healthy couple (mother: 37 years, $152 \mathrm{~cm}$; father: 39 years, $170 \mathrm{~cm}$ ). Developmental milestones were retarded; she can sit at 7 months, walk at 18 months, and speak at 27 months. At the age of five-and-a-half years, she was brought to medical attention because of ptosis. At that time, she could only count numbers within 10 and her height was $98 \mathrm{~cm}$ (less than third centile), weight was $13.5 \mathrm{~kg}$ (less than third centile), and head circumference was $46 \mathrm{~cm}$ (less than third centile). The width of palpebral fissure was $7-8 \mathrm{~mm}$ in the right eye and 2-3 $\mathrm{mm}$ in the left eye when raising her eyebrows. The axial length was $19.89 \mathrm{~mm}$ in the right eye and $19.74 \mathrm{~mm}$ in the left eye. She was not cooperative when examining visual acuity, ocular movement, anterior segment, and fundus of the eyes. But both eyes had pupil size and light reaction were normal. Other phenotypic manifestations were as followings (Figure 1A): rectangle face, epicanthal folds, low nasal bridge, broad neck with a low posterior hairline, and mental retardation (intelligence within the level of 2-year-old child). Auscultation revealed no heart murmur and normal respiratory sounds. Neither epileptic seizure nor dystonia was noted. Her cerebral imaging was performed and revealed no abnormalities. The results of laboratory evaluations, including complete blood count, electrolytes, liver function, renal function, blood level of thyroid hormone, and gonadal hormone, were all normal.

Chromosomal analysis of peripheral blood cells was carried out as follows: $0.3 \mathrm{~mL}$ of whole blood was used to inoculate each $5 \mathrm{~mL}$ cell culture fluid. Then, 68-69 hours after culture initiation, the blood culture was synchronized with colchicine and returned to the incubator for another

A

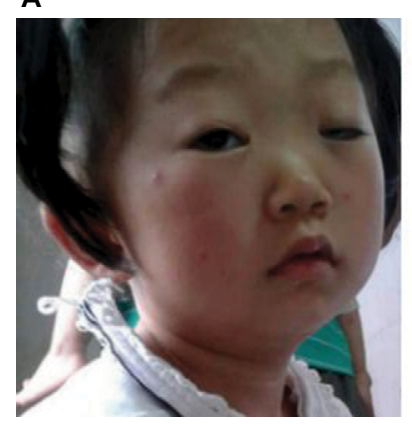

B

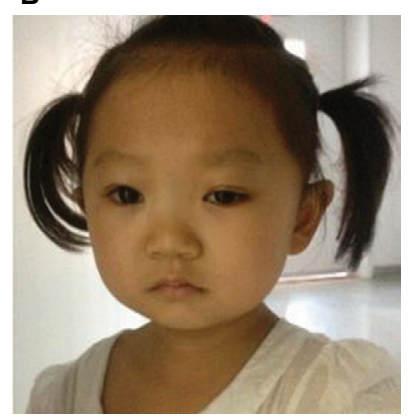

Figure I Phenotypical characteristics of the proband before (A) and after (B) blepharoplasty.
3-4 hours. Then, the blood cells were separated, fixed, and dyed. The procedure was also performed on the proband's mother. The proband analysis revealed a 46, XX, del (18) (p11.2) complement (Figure 2). The proband's mother revealed normal 46-XX karyotype. Her father and younger brother ( 2 years old) were phenotypically normal. No family history of hereditary disease or mental retardation was noted.

Blepharoplasty was performed because of ptosis in both eyes, and she had a good postoperative recovery, with the width of both palpebral fissures being $9 \mathrm{~mm}$ (Figure 1B).

\section{Discussion}

This patient has a major clone with deletion of part of the $\mathrm{p}$-arm (18p11.2), resulting in $18 \mathrm{p}$ deletion syndrome. The poor intellectual performance was in accordance with the usual phenotype of del(18p). Tsukahara et al ${ }^{12}$ reported about a Japanese child also bearing del (18p11.2) with an IQ of 74 with significant speech delay, placing him on a borderline intellectual functioning level. Maranda et a ${ }^{13}$ reported about a mother and her two daughters who had mild-to-moderate mental retardation, and all of them had the same chromosomal deletion: 46 , $\mathrm{XX}$, del (18) (p11.2). Peng et a $\mathrm{l}^{14}$ studied a girl with mosaic 46, XX, del (18) (p11.2)/46, XX, i (18q), and mild mental retardation and communication disorders were observed.

Epilepsy, together with mental retardation, commonly occurs in chromosomal aberrations. ${ }^{15}$ However, this girl has no history of epilepsy. Grosso et $\mathrm{al}^{16}$ reported that the short arm of chromosome was less likely to be associated with epilepsy. Hasi-Zogaj et al ${ }^{17}$ reviewed 106 18p deletions and found that seizures were not particularly common.

Short stature is another feature of this patient. There were reports suggesting that growth hormone (GH) deficiency occurs with deletions of the distal region of $18 p$ and is involved in the main clinical features of the syndrome. ${ }^{18}$ The growth delay of our patient could be the result of the region of deletion involved. Though several cases of $18 p$ monosomy with GH deficiency reported that the patients showed excellent catch-up growth after GH treatment; ${ }^{19-20}$ however, there is no indication of GH treatment according to the guideline of US Food and Drug Administration and Growth Hormone Research Society. ${ }^{21,22}$ Additionally, there is controversy regarding $\mathrm{GH}$ treatment of patients with gene defects ${ }^{23}$; thus, after fully understanding the possible consequences of the GH application, the parents of our case are cautious and taking a "wait-and-see" approach.

Other phenotypic features were quite similar with other cases of del(18p). It commonly includes a microcephaly, ptosis, a broad, flat nose, a "carp-shaped" mouth, large, 


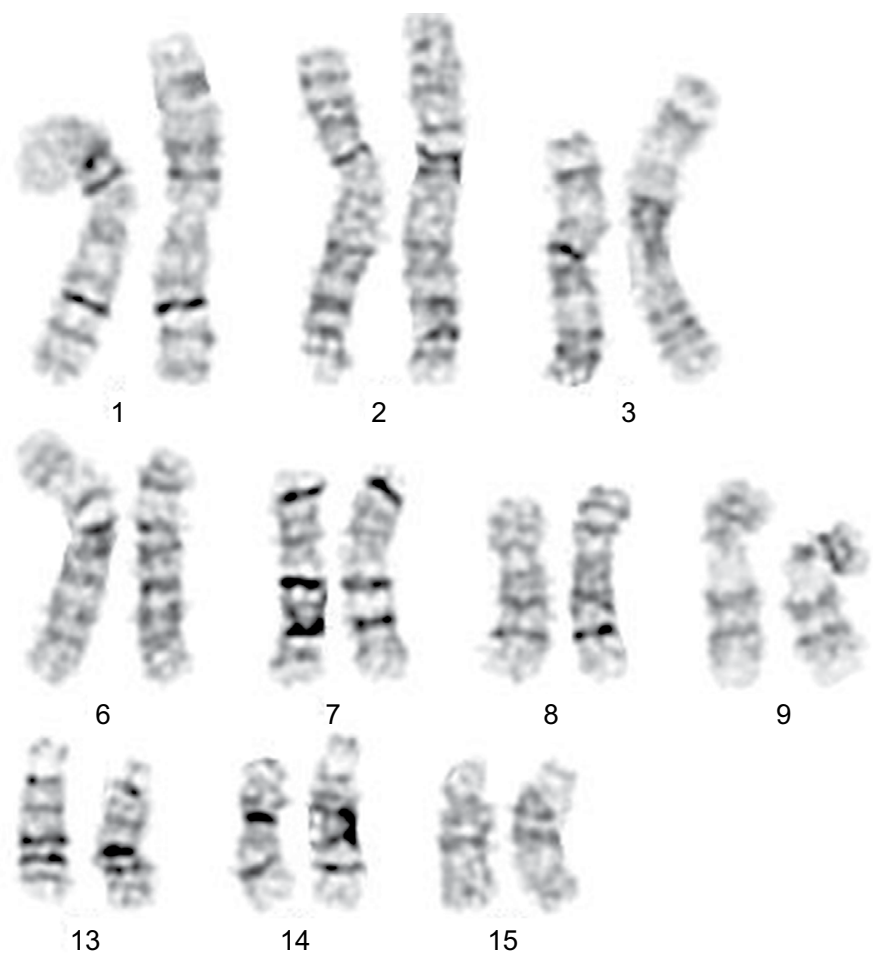

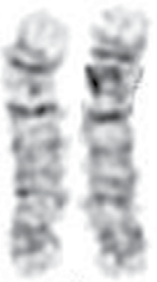

4

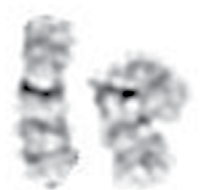

10

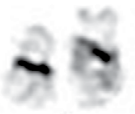

21

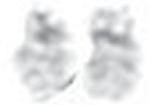

22

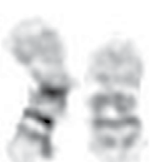

16

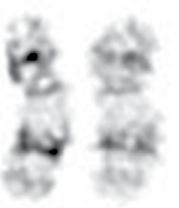

11

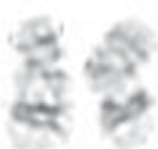

17

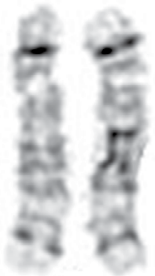

5

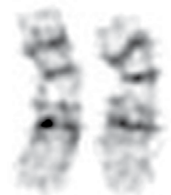

12

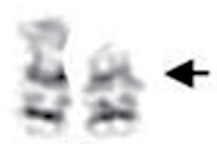

18

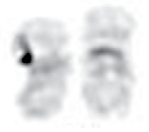

19

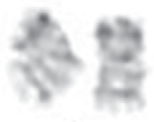

20
Figure 2 Chromosomal characteristics of the proband showing 18 p deletion.

protruding ears, widely-spaced eyes, and/or other abnormalities. Other neurologic findings and/or extremely variable midline facial defects include the presence of maxillary incisor, hypotelorism, an abnormal groove in the upper lip, cleft palate, and/or in severe cases, absence of the nose and/ or cyclopia. For some of the abnormal appearances, plastic surgery might be an option. In our case, the girl's facial appearance greatly improved after blepharoplasty.

Detailed breakpoints location and deleted genes identification help to pick up the del(18p). There are 19 genes related to this syndrome, contributing to the variable clinical pictures. USP 14 gene encodes a member of proteases, and mice with a mutation were retarded for growth. ${ }^{24}$ Gripp et al ${ }^{25}$ reported that TGIF1 links to NODAL signal pathway to the bifurcation of the human forebrain and the establishment of ventral midline structures. However, the information about breakpoints or genotype-phenotype correlations is limited. This report presents a case deletion of part of the p-arm (18p11.2). It is usually caused by spontaneous (de novo) errors very early in the development of the embryo that appear to occur randomly for unknown reasons. Thus, further study is needed to clarify the etiology and the correlation between genes and symptoms. Besides, the patient should be followed up for a long term.

\section{Conclusion}

This report sheds new lights on the del(18p) syndrome. Plastic surgery may be an option for some of the abnormalities to improve the appearance, as well as the life quality. Genetic counseling for these patients should be taken into account.

\section{Acknowledgment}

This research received no specific grant from any funding agency in the public, commercial, or not-for-profit sectors.

\section{Disclosure}

The authors report no conflicts of interest in this work.

\section{References}

1. Babovic-Vuksanovic D, Jenkins SC, Ensenauer R, Newman DC, Jalal SM Subtelomeric deletion of $18 \mathrm{p}$ in an adult with paranoid schizophrenia and mental retardation. Am J Med Genet A. 2004;124A(3):318-322.

2. Thompson RW, Peters JE, Smith SD. Intellectual, behavioral, and linguistic characteristics of three children with $18 \mathrm{p}$-syndrome. $J$ Dev Behav Pediatr. 1986;7(1):1-7. 
3. Wester U, Bondeson ML, Edeby C, Annerén G. Clinical and molecular characterization of individuals with $18 \mathrm{p}$ deletion: a genotype-phenotype correlation. Am J Med Genet A. 2006;140(11):1164-1171.

4. Turleau C. Monosomy 18p. Orphanet J Rare Dis. 2008;3:4.

5. De Grouchy J, Lamy M, Thieffry S, et al. Dysmorphie complexe avec oligophrenie: deletion des bras courts d'un chromosome 17-18. [Deletion of the short arms of chromosome 17-18: complex deformities with oligophrenia]. Arch Fr Pediatr. 1963;20:740-745.

6. de Ravel TJ, Thiry P, Fryns JP. Follow-up of adult males with chromosome 18p deletion. Eur J Med Genet. 2005;48(2):189-193.

7. Klein C, Page CE, LeWitt P, et al. Genetic analysis of three patients with an 18p-syndrome and dystonia. Neurology. 1999;52(3): 649-651.

8. Chen CP, Chern SR, Wang W, et al. Prenatal diagnosis of partial monosomy 18p(18p11.2-->pter) and trisomy 21q(21q22.3-->qter) with alobar holoprosencephaly and premaxillary agenesis. Prenat Diagn. 2001;21(5):346-350.

9. Chen CP, Lin SP, Tsai FJ, Wang TH, Chern SR, Wang W. Characterization of a de novo unbalanced Y;autosome translocation in a $45, \mathrm{X}$ mentally retarded male and literature review. Fertil Steril. 2008;90(4):. e11-.e18.

10. Chen CP, Kuo YT, Lin SP, et al. Mosaic ring chromosome 18, ring chromosome 18 duplication/deletion and disomy 18: perinatal findings and molecular cytogenetic characterization by fluorescence in situ hybridization and array comparative genomic hybridization. Taiwan J Obstet Gynecol. 2010;49(3):327-332.

11. Chen CP, Kuo YK, Su YN, et al. Prenatal diagnosis and molecular cytogenetic characterization of a derivative chromosome der(18;18) (q10;q10)del(18)(q11.1q12.1)del(18)(q22.1q22.3) presenting as apparent isochromosome $18 \mathrm{q}$ in a fetus with holoprosencephaly. Taiwan $J$ Obstet Gynecol. 2011;50(2):182-187.

12. Tsukahara M, Imaizumi K, Fujita K, Tateishi H, Uchida M. Familial Del(18p) syndrome. Am J Med Genet. 2001;99(1):67-69.

13. Maranda B, Lemieux N, Lemyre E. Familial deletion 18 p syndrome: case report. BMC Med Genet. 2006;7:60.
14. Peng D, Long PP, Wen B, Yu RH. A study of a rare chromosomal disorder: mosaic 46, XX, del (18)(p11.2)/46, XX, i(18q). J Genet. 2013; 92(3):611-615.

15. Schinzel A, Niedrist D. Chromosome imbalances associated with epilepsy. Am J Med Genet. 2001;106(2):119-124.

16. Grosso S, Pucci L, Di Bartolo RM, et al. Chromosome 18 aberrations and epilepsy: a review. Am J Med Genet A. 2005;134A(1):88-94.

17. Hasi-Zogaj M, Sebold C, Heard P, et al. A review of $18 \mathrm{p}$ deletions. Am J Med Genet C Semin Med Genet. 2015;169(3):251-264.

18. Portnoï MF, Gruchy N, Marlin S, et al. Midline defects in deletion 18p syndrome: clinical and molecular characterization of three patients. Clin Dysmorphol. 2007;16(4):247-252.

19. Schober E, Scheibenreiter S, Frisch H. 18p monosomy with GHdeficiency and empty sella: good response to GH-treatment. Clin Genet. 1995;47(5):254-256.

20. Artman HG, Morris CA, Stock AD. 18p-syndrome and hypopituitarism. J Med Genet. 1992;29(9):671-672.

21. Growth Hormone Research Society. Consensus guidelines for the diagnosis and treatment of growth hormone $(\mathrm{GH})$ deficiency in childhood and adolescence: summary statement of the GH Research Society. GH Research Society. J Clin Endocrinol Metab. 2000;85(11):3990-3993.

22. Wilson TA, Rose SR, Cohen P, et al; Lawson Wilkins Pediatric Endocrinology Society Drug and Therapeutics Committee. Update of guidelines for the use of growth hormone in children: the Lawson Wilkins Pediatric Endocrinology Society Drug and Therapeutics Committee. J Pediatr. 2003;143(4):415-421.

23. Savage MO, Camacho-Hübner C, David A, et al. Idiopathic short stature: will genetics influence the choice between GH and IGF-I therapy? Eur J Endocrinol. 2007;157(suppl 1):S33-S37.

24. Wilson SM, Bhattacharyya B, Rachel RA, et al. Synaptic defects in ataxia mice result from a mutation in Usp14, encoding a ubiquitinspecific protease. Nat Genet. 2002;32(3):420-425.

25. Gripp KW, Wotton D, Edwards MC, et al. Mutations in TGIF cause holoprosencephaly and link NODAL signalling to human neural axis determination. Nat Genet. 2000;25(2):205-208.
International Medical Case Reports Journal

\section{Publish your work in this journal}

The International Medical Case Reports Journal is an international, peer-reviewed open-access journal publishing original case reports from all medical specialties. Previously unpublished medical posters are also accepted relating to any area of clinical or preclinical science. Submissions should not normally exceed 2,000 words or

\section{Dovepress}

4 published pages including figures, diagrams and references. The manuscript management system is completely online and includes a very quick and fair peer-review system, which is all easy to use. Visit http://www.dovepress.com/testimonials.php to read real quotes from published authors. 